\title{
Procalcitonin for detecting medullary thyroid carcinoma: a systematic review
}

\author{
Pierpaolo Trimboli $^{1,2}$, Ettore Seregni ${ }^{3}$, Giorgio Treglia ${ }^{1}$, Maria Alevizaki ${ }^{4}$ and \\ Luca Giovanella'
}

'Department of Nuclear Medicine and Thyroid Centre, Oncology Institute of Southern Switzerland, Bellinzona, 6500 , Switzerland

${ }^{2}$ Section of Endocrinology and Diabetology, Ospedale Israelitico, Rome, Italy

${ }^{3}$ Nuclear Medicine, Fondazione IRCCS Istituto Nazionale Tumori, Milan, Italy

${ }^{4}$ Endocrine Unit, Department of Clinical Therapeutics, School of Medicine, Alexandra General Hospital,

Athens University, Athens, Greece

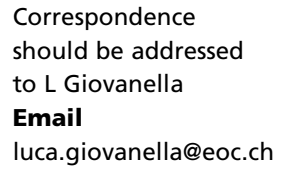

\begin{abstract}
The aim of the present study was to perform a systematic review of published studies to provide a robust estimation of the use of procalcitonin (ProCT) as a diagnostic marker of medullary thyroid carcinoma (MTC), with particular focus on its specificity and negative predictive value in excluding MTC. A comprehensive computer literature search was conducted to find relevant published articles on the topic. We used a search algorithm based on a combination of the terms 'medullary,' 'thyroid,' and 'ProCT.' The search was updated until February 2015. To expand our search, references of the retrieved articles were also screened. A total of 39 articles were retrieved, of which nine original papers published from 2003 to 2014 were selected for the review. Some of these studies used ProCT in the preoperative diagnosis of MTC, whereas others measured ProCT during the follow-up of patients who had been previously treated for MTC. Other laboratory measurements were performed in some of the included studies. The results of the majority of the studies indicate that ProCT measurement appears to be a very promising and reliable serum marker for the diagnosis of MTC, and it is not inferior to calcitonin (CT). The sample handling is less laborious, and in the few CT-negative cases reviewed, the assay had even greater sensitivity. It would be worthwhile to establish cutoff levels using larger patient series, because we speculate that this assay could potentially replace CT measurement in the future.
\end{abstract}

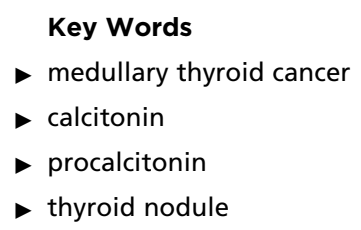

Endocrine-Related Cancer (2015) 22, R157-R164

\section{Introduction}

Medullary thyroid carcinoma (MTC) is a malignancy that originates from thyroid parafollicular $\mathrm{C}$ cells and accounts for about $5 \%$ of thyroid cancers (Kloos et al. 2009). In the majority of cases (i.e., four out of every five), this cancer occurs as a sporadic tumor, whereas the remaining ones are part of familial disorders (Kloos et al. 2009). Diagnosing MTC is still a challenge in clinical practice. Cytological examination by fine needle aspiration (FNAC) has a very low detection rate for MTC (Pusztaszeri et al. 2014, Trimboli et al. 2015); ultrasonography does not achieve high reliability in this context (Trimboli et al. 2014); and finally, the measurement of serum calcitonin (CT) should represent the most accurate tool for detecting MTC, but its use in patients with thyroid lesions is still a matter of

Published by Bioscientifica Ltd 
debate (Trimboli et al. 2014). Specifically, no CT thresholds have been identified for excluding MTC with certainty, and different potential cutoff values have been reported in literature. In addition, serum CT-negative MTC cases have been described (Trimboli \& Giovanella 2015). For these reasons, a non-negligible quantity of MTC is incidentally discovered after thyroidectomy, and the routine determination of CT is highly debated (Kloos et al. 2009). Thus, more tools for preoperatively diagnosing MTC are required in order to better plan the initial treatment of patients; furthermore, there is a great need for accurate markers with high specificity and negative predictive value to exclude MTC in patients with thyroid nodules and to carefully manage MTC patients during follow-up.

Recently, the determination of ProCT, a precursor of CT, has been investigated in the diagnosis and management of MTC. ProCT is a 116 amino acid peptide that originates from the $C$ cells of the thyroid gland, and it is a very stable protein that features a concentration-independent in vivo half-life of 20-24 h (Trimboli \& Giovanella 2015). In previous studies better performance of ProCT in comparison with CT have been recorded. Specifically, when the same antibodies were used, all of the commercial ProCT assays yielded similar results. In addition, ProCT samples do not need to be kept cold on ice during the entire process chain and are easier to manage in clinical practice. These characteristics give ProCT great potential to replace CT as a marker for detecting and managing MTC patients. To date, no review on this topic has, to our knowledge, been published.

The aim of the present study was to perform a systematic review of published studies to provide a robust estimate of using ProCT as a diagnostic marker of MTC for both preoperative diagnosis and recurrence detection. In particular, the present study focused on ProCT specificity and negative predictive value in excluding MTC.

\section{Materials and methods}

We searched studies that reported the measurement of ProCT in preoperative and/or postoperative diagnoses of MTC. A comprehensive computer literature search of the PubMed/MEDLINE, Embase, and Scopus databases was conducted to find published articles on this topic. The search algorithm was based on the combinations of the terms 'medullary' AND 'thyroid' AND 'ProCT.' We did not use a beginning date limit, and the search was updated until February 18, 2015. To identify additional studies and expand our search, references of the retrieved articles were also screened. All original articles that described serum
ProCT in MTC were eligible for inclusion. Case reports were initially excluded. The authors of the present study independently reviewed the retrieved articles. For each included study, information was abstracted concerning the study data (including authors, year of publication, journal of publication, type of article, and study design).

\section{Results}

\section{Eligible articles}

The comprehensive computer literature search revealed 39 articles. The titles and abstracts of these articles were reviewed, and nine original papers were selected; their fulltext versions were then retrieved, and their references lists were scanned (Bihan et al. 2003, Bolko et al. 2003, Algeciras-Schimnich et al. 2009, Kaczka et al. 2010, 2012, Walter et al. 2010, Kratzsch et al. 2011, Giovanella et al. 2013, Machens et al. 2014). These papers were published from 2003 to 2014, and they were all original articles (Table 1). Almost all of the studies were from European researchers (Bihan et al. 2003, Bolko et al. 2003, Kaczka et al. 2010, 2012, Walter et al. 2010, Kratzsch et al. 2011, Giovanella et al. 2013, Machens et al. 2014), and one was conducted by US investigators (Algeciras-Schimnich et al. 2009). Some of these studies used ProCT (Bihan et al. 2003, Giovanella et al. 2013, Machens et al. 2014) in the preoperative diagnosis of MTC, whereas the remaining ones (Bihan et al. 2003, Bolko et al. 2003, Kaczka et al. 2010, 2012, Walter et al. 2010, Kratzsch et al. 2011) measured ProCT during follow-up of patients who had been previously treated for MTC. Additional laboratory investigations were performed in some of the included studies. For CT measurement, different assays were employed and different reference values were adopted. Preoperative ProCT stimulation by pentagastrin was performed in two studies (Kratzsch et al. 2011, Giovanella et al. 2013). The different characteristics between the studies (i.e., objective, ProCT cutoff level, etc.) did not allow a meta-analysis.

\section{Use of ProCT for the postoperative detection of recurrent MTC}

Seven papers (Bihan et al. 2003, Bolko et al. 2003, Algeciras-Schimnich et al. 2009, Kaczka et al. 2010, 2012, Walter et al. 2010, Kratzsch et al. 2011) reported ProCT measurement in MTC patients during follow-up after surgery. A total of 265 MTC cases, of which 114 involved cured patients and 151 were recurrent/persistent cases,

Published by Bioscientifica Ltd. 
Table 1 Main characteristics of the studies included in the systematic review

\begin{tabular}{|c|c|c|}
\hline First author & Year & Country \\
\hline Bolko & 2003 & Poland \\
\hline Bihan & 2003 & France \\
\hline Algeciras-Schimnich & 2009 & USA \\
\hline Kaczka & 2010 & Poland \\
\hline Walter & 2010 & $\begin{array}{l}\text { Switzerland- } \\
\text { The Netherlands }\end{array}$ \\
\hline Kratzsch & 2011 & Germany \\
\hline Kaczka & 2012 & Poland \\
\hline Giovanella & 2013 & Switzerland \\
\hline Machens & 2014 & Germany \\
\hline
\end{tabular}

\section{Study aim}

To evaluate PCT in patients followed-up for MTC

To evaluate the clinical utility of CT precursor serum levels

To evaluate PCT in patients followed-up for MTC and in patients with other conditions

To evaluate PCT in patients followed-up for MTC and in patients with goiters at histology

To evaluate PCT in patients followed-up for MTC

To test if PCT could be a marker of MTC after surgery

To evaluate PCT in patients followed-up for MTC

To evaluate PCT in diagnosing and excluding MTC in thyroid nodule patients

To evaluate PCT in diagnosing and excluding MTC in thyroid nodule patients

$\mathrm{PCT}$, procalcitonin; $\mathrm{CT}$, calcitonin; MTC, medullary thyroid carcinoma.

were reported. The most relevant paper was published by Algeciras-Schimnich et al. (2009); it collected data on a series of 133 MTC cases ( 42 cured and 91 active), and 83 out of 91 (91.2\%) of the recurrent MTCs had ProCT of over $0.15 \mathrm{ng} / \mathrm{ml}$, whereas none of the cured MTCs had positive ProCT (specificity 100\%). Among the active MTCs, those with stable disease had the lowest mean ProCT levels $(3.6 \mathrm{ng} / \mathrm{ml})$, patients with recurrent/metastatic disease had the highest mean value $(241.7 \mathrm{ng} / \mathrm{ml})$, and patients with newly diagnosed cancer had intermediate levels $(13.8 \mathrm{ng} / \mathrm{ml})$. The ProCT concentration that gave the best diagnostic accuracy was $0.16 \mathrm{ng} / \mathrm{ml}$, which corresponds to the upper reference limit for normal subjects $(\leq 0.15 \mathrm{ng} / \mathrm{ml})$. The authors concluded that ProCT is a promising complementary MTC tumor marker because of its great analytical stability. An important contribution was also made by the Kratzsch et al. (2011) study. Those authors compared ProCT to several CT assays (Immulite, Liaison, and IRMA Medipan) in different groups of patients with hypercalcitoninemia, including: subjects affected by recurrent/persistent MTC, those with chronic kidney disease (CKD), and those with Hashimoto's thyroiditis. The ten MTCs in that study had CT levels that ranged from 18 to $1511 \mathrm{pg} / \mathrm{ml}$, and ProCT levels were between 0.226 and $11.6 \mathrm{ng} / \mathrm{ml}$. The authors found the highest CT and ProCT values in CKD patients and showed a diagnostic sensitivity for MTC of 100\% with ProCT and IRMA-CT but only 90 and $80 \%$ for Immulite_CT and Liaison-CT respectively. A ProCT value of less than $0.25 \mathrm{ng} / \mathrm{ml}$ could exclude MTC. Of relevance, ProCT concentrations appeared to have better stability than CT levels did. In addition, Kaczka et al. (2010, 2012) reported two series, the first of which (Kaczka et al. 2010) recorded undetectable $(<0.1 \mathrm{ng} / \mathrm{ml})$ ProCT in 20 out of 23 MTC patients in remission (87\% specificity) and detectable (range $0.63-5.52 \mathrm{ng} / \mathrm{ml}$ ) ProCT in persistent MTC (100\% sensitivity). Later, these Polish authors evaluated ProCT in four active MTC cases after surgery, in two MTC patients before and after surgery, and in 23 other MTC patients in remission (Kaczka et al. 2012); their most relevant findings were that 20 out of 23 (87\%) disease-free patients had undetectable $(<0.1 \mathrm{ng} / \mathrm{ml})$ ProCT levels, and the remaining three had $0.15,0.16$, and $0.27 \mathrm{ng} / \mathrm{ml}$. On the other hand, CT measurement in these patients showed undetectable $(<5 \mathrm{pg} / \mathrm{ml})$ values in 15 cases, values between the lower reference limit and $10 \mathrm{pg} / \mathrm{ml}$ in five cases, and levels above $10 \mathrm{pg} / \mathrm{ml}$ in three patients. Also, the mean ProCT concentration was 3.5 in the active MTC group and $0.06 \mathrm{ng} / \mathrm{ml}$ in the MTC patients in remission. A study by Walter et al. (2010) evaluated 69 MTC patients during follow-up, and ProCT was detectable (i.e., $>0.06 \mathrm{ng} / \mathrm{ml}$ ) in 67 cases; the best cutoff for discriminating MTC from the control was $0.5 \mathrm{ng} / \mathrm{ml}$ ( $84 \%$ sensitivity and specificity), whereas the threshold for distinguishing MTC from C cell hyperplasia was $0.16 \mathrm{ng} / \mathrm{ml}$ (59\% sensitivity and $100 \%$ specificity). Also, the ProCT:CT ratio was as an accurate predictor of progression-free survival and was correlated with the clinical outcome. Finally, two older papers should also be cited. Very high sensitivity (100\%) of ProCT in detecting recurrent MTC was also recorded by Bolko et al. (2003). They used a sandwich assay with anti-catacalcin antibody as the marker and anti-CT antibody as the solid phase; therefore, the results were not perfectly comparable to those in more recent studies. A study by Bihan et al. (2003) used a chemiluminescent assay to detect both intact ProCT molecule and CT-conjoined C-terminal cleavage peptide1 (CCP1), but the assay did not distinguish between

Published by Bioscientifica Ltd. 
the two; therefore, unfortunately, the ProCT results were not specified. All of the results for ProCT in recurrent and cured MTC cases are shown in Table 2.

\section{Use of ProCT for the preoperative diagnosis of MTC in patients with thyroid nodules}

Two studies (Giovanella et al. 2013, Machens et al. 2014) aimed to evaluate ProCT as a marker for the initial diagnosis of MTC in a series of thyroid nodule patients. All of the patients underwent surgery and had a final histological diagnosis of MTC. Relevant data about the prognoses of the patients was described in one of the papers (Machens et al. 2014). In that study, Machens and colleagues evaluated 457 consecutive patients with previously untreated MTC, 112 of whom had ProCT and CT serum levels that were determined before the initial surgery. Receiver operating characteristic analyses revealed similar diagnostic accuracy for ProCT and CT and yielded similar areas under the curve for primary tumors, extrathyroidal extension, number of lymph nodes involved, and distant metastasis. However, ProCT levels were only correlated with the number of lymph nodes involved and the distant extent of disease. Also, 107/112 cases had ProCT levels of more than $0.1 \mathrm{ng} / \mathrm{ml}$, with a sensitivity of $95.5 \%$. As the ProCT levels increased, the biochemical cure rates declined $(71 \%$ for $1 \mathrm{ng} / \mathrm{ml} ; 36 \%$ for $5 \mathrm{ng} / \mathrm{ml} ; 23 \%$ for $10 \mathrm{ng} / \mathrm{ml} ; 10 \%$ for $50 \mathrm{ng} / \mathrm{ml})$. In another prospective study (Giovanella et al. 2013), both CT and ProCT were measured in a consecutive series of 1236 patients' thyroid nodules, and 14 cases displayed increased (i.e., above $10 \mathrm{pg} / \mathrm{ml}$ ) calcitonin levels and were selected for pentagastrin stimulation; upon histology, two MTCs were recorded, and they had basal CT of over $100 \mathrm{pg} / \mathrm{ml}$ and ProCT of $>0.1 \mathrm{ng} / \mathrm{ml}$. The main results of that study were that basal and pentagastrinstimulated CT had some false-positive results, whereas all of the patients without MTC had undetectable levels of both basal and stimulated ProCT (100\% positive predictive value (PPV) and $100 \%$ negative predictive value (NPV)). The authors recommended measuring ProCT and avoiding CT stimulation in patients with moderately elevated (i.e., between 10 and $100 \mathrm{pg} / \mathrm{ml}$ ) basal CT.

\section{Discussion}

Since its first description (Horn \& Ravdin. 1951), diagnosing MTC has been a challenge (Pusztaszeri et al. 2014, Trimboli et al. 2014, 2015). Calcitonin, a 32-amino-acid monomeric peptide that results from the processing of ProCT, has traditionally been reported as the most accurate serum tool for identifying MTC both before and after surgical treatment. However, some relevant limits of CT measurement in clinical practice have affected its accuracy (Costante et al. 2007, Cheung et al. 2008). CT belongs to the calcitonin gene-related peptide (CGRP) superfamily and is generated by the alternative splicing of the calcitonin gene (CALCI). Calcitonin is the main peptide product of thyroid C cells, but alternative expression of the gene results in the formation of CGRP in neural tissue. The biosynthetic secretory pathway for CT involves a complex series of progressive modifications: after the biosynthesis and folding of precursors, subsequent proteolytic processing occurs both within the Golgi apparatus and later within the secretory granules because of the actions of prohormone convertase (PC) enzymes. The precursor of CT is pre-procalcitonin (PreProCT), and it contains 141 amino acids with a signal peptide of 25 residues. ProCT (1-116) is processed to mature calcitonin, amino acids 60-91, and to CCP1, amino acids 96-116. Figure 1 depicts and summarizes the process that leads to $\mathrm{CT}$ production. In the preanalytical phase, the marked variation of CT that occurs during the day because of its pulsative secretion may be

Table 2 The results for ProCT use in recurrent and cured MTC after surgery

\begin{tabular}{|c|c|c|c|c|c|c|}
\hline \multirow[b]{3}{*}{ First author } & \multicolumn{3}{|c|}{ Recurrent MTC } & \multicolumn{3}{|c|}{ Cured MTC } \\
\hline & \multirow[b]{2}{*}{$\operatorname{MTC}(n)$} & \multicolumn{2}{|c|}{ ProCT } & \multirow[b]{2}{*}{$\operatorname{MTC}(n)$} & \multicolumn{2}{|c|}{ ProCT } \\
\hline & & Positive & Sensitivity & & Negative & Specificity \\
\hline Bolko & 10 & 10 & 100 & 14 & 8 & 57.1 \\
\hline Algeciras-Schimnich & 91 & 83 & 91.2 & 42 & 42 & 100 \\
\hline Kaczka & 9 & 9 & 100 & 23 & 20 & 87.0 \\
\hline Walter & 34 & ND & 84.0 & 35 & ND & 84.0 \\
\hline Kratzsch & 10 & 10 & 100 & - & - & - \\
\hline Kaczka & 6 & 6 & 100 & 23 & 20 & 87.0 \\
\hline
\end{tabular}

ND, not detailed. 


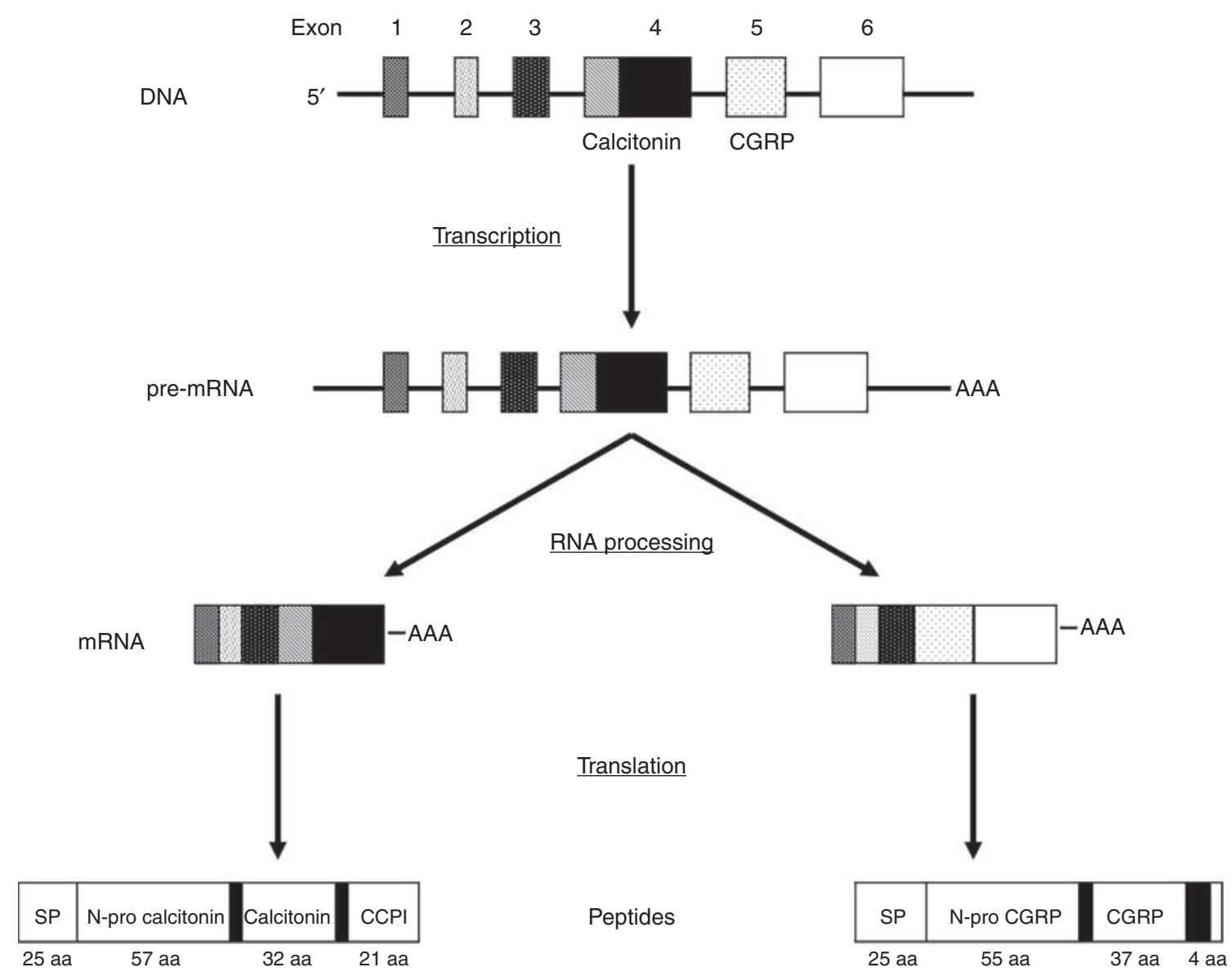

Figure 1

The process that leads to calcitonin production.

influenced by food intake; also, CT is rapidly degraded at room temperature, and it decays by $23 \%$ after $12 \mathrm{~h}$, by $35 \%$ after $24 \mathrm{~h}$, and by $65 \%$ after 7 days (Perdrisot et al. 1990, Zink et al. 1992). Therefore, blood samples should be drawn in the morning after overnight fasting, and it is necessary to centrifuge the samples immediately after blood coagulation and then to freeze and transport them in ice to the laboratory. The analytical methods of CT assay have evolved over time, and most laboratories that perform routine CT measurement have moved away from manual IRMA methods (Perdrisot et al. 1990, Zink et al. 1992) to automated chemiluminescent immunoassay (ICLA) platforms that have similar analytical performance (Grauer et al. 1998). However, the variable levels of the different products of the CT gene result in several circulating immunoreactive isoforms and fragments (Perdrisot et al. 1990, Zink et al. 1992), and, consequently, poor interassay and inter-laboratory agreement was demonstrated between the reviewed studies (Giovanella et al. 2012).
In the post-analytical phase, establishing normal limits of CT in healthy subjects is still a challenge because of the significant variability in diagnostic accuracy and reference intervals of the different commercially available assays (Giovanella et al. 2012). Healthy subjects almost always have serum CT concentrations of less than $10 \mathrm{pg} / \mathrm{ml}$, but only a CT value that exceeds $100 \mathrm{pg} / \mathrm{ml}$ is considered to be a reliable marker for the presence of MTC. A stimulation test with an infusion of pentagastrin or calcium gluconate is required in patients with mildly elevated basal CT levels; stimulated CT values of $>100 \mathrm{pg} / \mathrm{ml}$ should prompt surgery (Trimboli et al. 2014). These diagnostic guidelines, which have been widely adopted in clinical practice, were established by using the manual IRMA provided by CisBio (Perdrisot et al. 1990, Zink et al. 1992). In addition, the upper reference limits for females and males should be different, because the number of $\mathrm{C}$ cells is approximately two times higher in men than in women (Trimboli \& Giovanella 2015). As a practical consequence and in order

Published by Bioscientifica Ltd 
Table 3 Levels of ProCT adopted as positive in the published studies

\begin{tabular}{l} 
First author \\
\hline Bolko $^{a}$ \\
Algeciras-Schimnich $^{a}$ \\
Kaczka $^{\mathrm{a}}$ \\
Walter $^{\mathrm{a}}$ \\
Kratzsch $^{\mathrm{a}}$ \\
Kaczka $^{\mathrm{a}}$ \\
Giovanella $^{\mathrm{b}}$ \\
Machens $^{\mathrm{b}}$
\end{tabular}

Proct levels
$>0.5$
$>0.15$
$>0.1$
$>0.5$
$>0.25$
$>0.1$
$>0.1$
$>0.1$

ProCT values are reported in $\mathrm{ng} / \mathrm{ml}$. apostoperative ProCT value.

${ }^{\mathrm{b}}$ Preoperative ProCT value.

to avoid false diagnoses, specific reference values are required before each new CT assay can be used in clinical practice. Finally, increased CT may be associated with several non-medullary conditions (Trimboli et al. 2014), including: bacterial infections, severe disease status, hypercalcemia (hyperparathyroidism) and renal failure, autoimmune thyroiditis, pregnancy and lactation, leukemia, systemic mastocytosis, small-cell lung carcinoma, and breast or pancreatic cancer. Hypergastrinemia, treatment with proton-pump inhibitors, and heterophilic antibody interference may be associated with hypercalcitoninemia as well.

In order to overcome such limits, potential alternative MTC serum markers, such as CEA, chromogranin A, and ProCT, have been investigated. Of these molecules, ProCT has appeared to be the most promising. In the more recent literature, ProCT has been reported to be an accurate new serum marker for the diagnosis and follow-up of MTC. Some studies that compared the abilities of ProCT and CT in order to distinguish MTC from other conditions revealed results (Perdrisot et al. 1990, Zink et al. 1992, Giovanella et al. 2010, Giovanella 2012). Unlike CT, ProCT is a very stable protein that has a concentrationindependent in vivo half-life of 20-24 h, and it does not need to be kept cold on ice or frozen. It is also easier to manage at the pre-analytical level. Because they use the same antibodies, all commercial ProCT assays yield similar results, which enables the standardization of biomarkerbased diagnosis, therapy, and monitoring of patients with MTC. This feature of ProCT differs clearly from CT and has high relevance in clinical practice. Some limitations, however, affect ProCT determination; in fact, a marked increase in this molecule has been reported in systemic infections (mainly bacteriemia) and inflammatory diseases, and these conditions represent the main indications for ProCT measurement (Plebani \& Fabbri 2015).

In the present report, we systematically reviewed the published articles on the use of ProCT in MTC patients. Different cutoffs of positivity for ProCT were adopted in the reviewed studies (Table 3). The majority of these reports described ProCT measurement during the followup of patients after surgical treatment. In this regard, cured patients very rarely had detectable ProCT, with a specificity of $100 \%$ in the largest study and specificity that ranged from 57 to $87 \%$ in the other three series; this was the most interesting result for clinical practice. Also, in patients with active/recurrent MTC, a 100\% sensitivity was recorded in four papers, and the two others listed sensitivities of 84 and 91\%. Patients with stable disease had ProCT values that were significantly lower than those in cases of MTC in progression. All of the results of ProCT in recurrent and cured MTC are shown in Table 2. Two of the studies reported the evaluation of ProCT as a marker for the initial preoperative detection of MTC. A significant finding in terms of prognosis was described as part of one study (Machens et al. 2014): 107 out of 112 MTC had ProCT values of more than $0.1 \mathrm{ng} / \mathrm{ml}$, with a sensitivity of 95.5\%, and the ProCT values correlated with the extent of the disease. Furthermore, the biochemical cure rates were inversely correlated with the ProCT levels. In the other study (Giovanella et al. 2013), pentagastrin-stimulated CT and ProCT were tested in patients with moderately elevated CT, and undetectable levels of both basal and stimulated ProCT had 100\% PPV and NPV in identifying MTC cases. In light of these data, serum ProCT could have the potential to replace serum CT as a new standard of care in the management of MTC. A relevant advantage of using ProCT assays is that all commercial assays yield quite similar results. One limitation might be that measurements of ProCT are not very widely available; however, because of its increasing use as a pivotal marker in internal

Table 4 Values of ProCT recorded in non-MTC patients in the published studies

\begin{tabular}{|c|c|c|}
\hline First author & $\begin{array}{l}\text { Athyreotic } \\
\text { patients }^{a}\end{array}$ & Healthy subjects \\
\hline Algeciras-Schimnich & $<0.1$ (mean) & $<0.1$ (mean) \\
\hline \multirow[t]{2}{*}{ Kaczka } & 0.06 (mean) & - \\
\hline & $0.00-0.28(\min -\max )$ & \\
\hline Walter & $0.07-0.60(\min -\max )$ & $0.06-0.28(\min -\max )$ \\
\hline
\end{tabular}

ProCT values are reported in $\mathrm{ng} / \mathrm{ml}$.

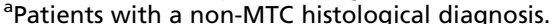

${ }^{b}$ The two studies by Kaczka et al. probably reported the same control group of thyroidectomized patients.

Published by Bioscientifica Ltd. 
medicine and antibiotic therapy, the availability of ProCT is expected to grow during the coming years (Plebani \& Fabbri 2015). The most critical challenge is that further studies are needed to identify the optimal cutoff level of ProCT, so that active (i.e., recurrent/persistent) MTC cases can be distinguished from cured ones. To date, data recorded in healthy and athyreotic subjects could be used in an initial approach to define an accurate threshold. As shown in Table 4, ProCT levels of up to $0.28 \mathrm{ng} / \mathrm{ml}$ have been recorded in athyreotic and healthy subjects.

Interestingly, ProCT appears to be useful in those rare MTC cases where CT is undetectable both preoperatively and postoperatively and where this marker of disease activity is therefore lacking. Brutsaert et al. (2015) tested ProCT levels of one patient before and after surgery: its value converted from detectable $(0.21 \mathrm{ng} / \mathrm{ml})$ to undetectable $(<0.1 \mathrm{ng} / \mathrm{ml})$ respectively. Bugalho et al. (2014) described a man with recurrent MTC with liver metastasis of $34 \mathrm{~mm}$, a low CT value ( $<50 \mathrm{ng} / \mathrm{ml})$, and a high ProCT value $(10.1 \mathrm{ng} / \mathrm{ml})$. These reports should receive attention specifically because they could help with the management, before and after surgery, of those MTC cases with negative/undetectable CT (Trimboli \& Giovanella 2015). Previously, Novotny et al. (2009) showed that ProCT can be used for monitoring sepsis in a patent affected by MTC. However, we still do not know whether common bacterial infections pose practical difficulties in the interpretation of ProCT levels. This issue has to be considered when CT and ProCT are used as MTC markers in patients with suspected infectious disease.

So far, CT has been considered an 'ideal' marker for diagnosing MTC in patients who are suspected to have MTC or are routinely screened for MTC as well as for the follow-up of those who have already been diagnosed with MTC. Results of previous studies have indicated the superiority of CT as compared with other markers, such as CGRP. However, CT assays have some intrinsic limitations that affect their reliability in the diagnosis and management of MTC patients, especially at the pre-analytical level. The ProCT data that are so far available from a sizable number of studies show very promising results, and it is tempting to speculate that the ProCT assay may in the future replace CT in the management of MTC patients.

All of the data retrieved in the present review are indicative of a potentially important role of ProCT measurement in the management of MTC patients. It would therefore be worthwhile to establish cutoff levels using larger patient series in a prospective manner. Until then, values in the normal population could be used as a reference range.
Declaration of interest

The authors declare that there is no conflict of interest that could be perceived as prejudicing the impartiality of this review.

\section{Funding}

This research did not receive any specific grant from any funding agency in the public, commercial or not-for-profit sector.

\section{References}

Algeciras-Schimnich A, Preissner CM, Theobald JP, Finseth MS \& Grebe SK 2009 Procalcitonin: a marker for the diagnosis and follow-up of patients with medullary thyroid carcinoma. Journal of Clinical Endocrinology and Metabolism 94 861-868. (doi:10.1210/jc.2008-1862)

Bihan H, Becker KL, Snider RH, Nylen E, Vittaz L, Lauret C, Modigliani E, Moretti JL \& Cohen R 2003 Calcitonin precursor levels in human medullary thyroid carcinoma. Thyroid 13 819-822. (doi:10.1089/ 105072503768499716)

Bolko P, Manuszewska-Jopek E, Michałek K, Waśko R, Jaskuła M \& Sowiński J 2003 Efficacy of procalcitonin measurement in patients after total thyroidectomy due to medullary thyroid carcinoma. Archivum Immunologiae et Therapiae Experimentalis 51 415-419.

Brutsaert EF, Gersten AJ, Tassler AB \& Surks MI 2015 Medullary thyroid cancer with undetectable serum calcitonin. Journal of Clinical Endocrinology and Metabolism 100 337-341. (doi:10.1210/jc.2014-3095)

Bugalho MJ, Madureira D, Domingues R, Pereira T \& Cortez L 2014 Medullary thyroid carcinoma preferentially secreting procalcitonin. Thyroid 24 1190-1191. (doi:10.1089/thy.2013.0664)

Cheung K, Roman SA, Wang TS, Walker HD \& Sosa JA 2008 Calcitonin measurement in the evaluation of thyroid nodules in the United States: a cost-effectiveness and decision analysis. Journal of Clinical Endocrinology and Metabolism 93 2173-2180. (doi:10.1210/jc.2007-2496)

Costante G, Meringolo D, Durante C, Bianchi D, Nocera M, Tumino S, Crocetti U, Attard M, Maranghi M, Torlontano M et al. 2007 Predictive value of serum calcitonin levels for preoperative diagnosis of medullary thyroid carcinoma in a cohort of 5817 consecutive patients with thyroid nodules. Journal of Clinical Endocrinology and Metabolism 92 450-455. (doi:10.1210/jc.2006-1590)

Giovanella L 2012 Serum procalcitonin and calcitonin normal values before and after calcium gluconate infusion. Experimental and Clinical Endocrinology \& Diabetes 120 169-170. (doi:10.1055/s-0031-1301290)

Giovanella L, Maffioli M, Suriano S \& Dorizzi RM 2010 Elevated calcitonin and procalcitonin levels in nonmedullary benign and malignant thyroid nodules. Clinical Endocrinology 72 852-853. (doi:10.1111/ j.1365-2265.2009.03733.x)

Giovanella L, Imperiali M, Ferrari A, Palumbo A, Lippa L, Peretti A, Graziani MS, Castello R \& Verburg FA 2012 Thyroid volume influences serum calcitonin levels in a thyroid-healthy population: results of a 3-assay, 519 subjects study. Clinical Chemistry and Laboratory Medicine 50 895-900. (doi:10.1515/cclm-2011-0920)

Giovanella L, Verburg FA, Imperiali M, Valabrega S, Trimboli P \& Ceriani L 2013 Comparison of serum calcitonin and procalcitonin in detecting medullary thyroid carcinoma among patients with thyroid nodules. Clinical Chemistry and Laboratory Medicine 51 1477-1481. (doi:10.1515/cclm-2012-06100)

Grauer R, Raue F \& Ziegler R 1998 Clinical usefulness of a new chemiluminescent two-site immunoassay for human calcitonin. Experimental and Clinical Endocrinology \& Diabetes 106 353-359. (doi:10.1055/s-0029-1211997)

Horn RC \& Ravdin IS 1951 Carcinoma of the thyroid gland in youth. Journal of Clinical Endocrinology and Metabolism 11 1166-1178. (doi:10.1210/jcem-11-10-1166) 
Kaczka K, Mikosiński S, Fendler W, Jałocha-Kaczka A \& Pomorski L 2010 Can procalcitonin be useful for medullary thyroid cancer? Endokrynologia Polska 61 430-436.

Kaczka K, Mikosiński S, Fendler W, Celnik A \& Pomorski L 2012 Calcitonin and procalcitonin in patients with medullary thyroid cancer or bacterial infection. Advances in Clinical and Experimental Medicine 21 169-178.

Kloos RT, Eng C, Evans DB, Francis GL, Gagel RF, Gharib H, Moley JF, Pacini F, Ringel MD, Schlumberger M et al. 2009 Medullary thyroid cancer: management guidelines of the American Thyroid Association. Thyroid 19 565-612. (doi:10.1089/thy.2008.0403)

Kratzsch J, Petzold A, Raue F, Reinhardt W, Bröcker-Preuss M, Görges R, Mann K, Karges W, Morgenthaler N, Luster M et al. 2011 Basal and stimulated calcitonin and procalcitonin by various assays in patients with and without medullary thyroid cancer. Clinical Chemistry $\mathbf{5 7}$ 467-464. (doi:10.1373/clinchem.2010.151688)

Machens A, Lorenz K \& Dralle H 2014 Utility of serum procalcitonin for screening and risk stratification of medullary thyroid cancer. Journal of Clinical Endocrinology and Metabolism 99 2986-2994. (doi:10.1210/jc. 2014-1278)

Novotny AR, Luppa P, Rosenberg R, Schneider H, Maak M, Bartels H, Holzmann B \& Friess H 2009 Procalcitonin can be used for monitoring sepsis in patients with medullary thyroid carcinoma. Thyroid 19 1287-1289. (doi:10.1089/thy.2009.0093)

Perdrisot R, Bigorgne JC, Guilloteau D \& Jallet P 1990 Monoclonal immunoradiometric assay of calcitonin improves investigation of familial medullary thyroid carcinoma. Clinical Chemistry 36 381-383.
Plebani M \& Fabbri LM 2015 Procalcitonin-guided antibiotic therapy: a potentially effective and efficient strategy. Clinical Chemistry and Laboratory Medicine 53 519-520. (doi:10.1515/cclm-2015-0061)

Pusztaszeri MP, Bongiovanni M \& Faquin WC 2014 Update on the cytologic and molecular features of medullary thyroid carcinoma. Advances in Anatomic Pathology 21 26-35. (doi:10.1097/PAP. 0000000000000004)

Trimboli P \& Giovanella L 2015 Serum calcitonin negative medullary thyroid carcinoma: a systematic review of the literature. Clinical Chemistry and Laboratory Medicine (In Press). (doi:10.1515/cclm-20150058)

Trimboli P, Giovanella L, Crescenzi A, Romanelli F, Valabrega S, Spriano G, Cremonini N, Guglielmi R \& Papini E 2014 Medullary thyroid cancer diagnosis: An appraisal. Head \& Neck 36 1216-1223. (doi:10.1002/hed. 23449)

Trimboli P, Treglia G, Guidobaldi L, Romanelli F, Nigri G, Valabrega S, Sadeghi R, Crescenzi A, Faquin WC, Bongiovanni M et al. 2015 Detection rate of FNA cytology in medullary thyroid carcinoma: a meta-analysis. Clinical Endocrinology 82 280-285. (doi:10.1111/cen.12563)

Walter MA, Meier C, Radimerski T, Iten F, Kränzlin M, Müller-Brand J, de Groot JW, Kema IP, Links TP \& Müller B 2010 Procalcitonin levels predict clinical course and progression-free survival in patients with medullary thyroid cancer. Cancer 116 31-40. (doi:10.1002/cncr.24738)

Zink A, Blind E \& Raue F 1992 Determination of serum calcitonin by immunoradiometric two-site assays in normal subjects and patients with medullary thyroid carcinoma. European Journal of Clinical Chemistry and Clinical Biochemistry 30 831-835.

Received in final form 27 April 2015

Accepted 30 April 2015

Made available online as an Accepted Preprint

1 May 2015
(C) 2015 Society for Endocrinology Printed in Great Britain 